Article

\title{
An Analysis of Relationship between the Environment and User's Behavior on Unimproved Streets: A Case Study of Da Nang City, Vietnam
}

\author{
Duy Thinh Do ${ }^{1, *}$, Suguru Mori ${ }^{2}$ and Rie Nomura ${ }^{2}$ \\ 1 Graduate School of Engineering, Hokkaido University, Sapporo 060-8628, Japan \\ 2 Faculty of Engineering, Hokkaido University, Sapporo 060-8628, Japan; \\ suguru-m@eng.hokudai.ac.jp (S.M.); nomurarie@eng.hokudai.ac.jp (R.N.) \\ * Correspondence: doduythinh@gmail.com or doduythinh@eng.hokudai.ac.jp; Tel.: +81-808-629-4578
}

Received: 14 November 2018; Accepted: 19 December 2018; Published: 24 December 2018

check for updates

\begin{abstract}
One of the most insoluble problems confronted by urban areas in developing countries is the shortage of open space; street space allows daily human activities, promotes social interaction, and is seen as a precondition for the sustainable development of the community. Although some seemingly public space is also built up in Vietnam, street space is often where resident's go to perform activities. This research aims at studying behaviors of users in old street space and the interaction with existing physical settings; as an input to future renovation and the development of street space in a manner that respects the cultural and social context of the Vietnamese people. User's behaviors in streets and physical characteristics of space were collected and processed in accordance with theories of behavior setting and proxemics using some methods including place-centered behavioral mapping (PcBM) and visual encounter surveys (VES). The analysis showed that three types of behavior, including (1) Type A where various frequent activities occurred, (2) Type B which discouraged most human activities, and (3) Type $C$ where neither frequent nor infrequent behaviors can represent environmental behavior patterns in the old street spaces of Vietnam and for each of these types of patterns improvements have been proposed by organizing street and pavements layouts detailed in this paper. The proposed improvements are based on the relationship between human behaviors and properties of the street space to assist designers, administers, and authorities in renovating and developing better and more sustainable street space.
\end{abstract}

Keywords: unimproved street; environmental behavior; behavior setting; proxemics; Danang

\section{Introduction}

\subsection{Background}

The quality of urban open space has been proved to provide social, psychological, and economic benefits [1] that contribute to the sustainability of the urban development [2,3]. The street not only serves its traffic function-connecting urban environment elements together-but also as open space providing a place for social interactions, community engagements, and daily activities such as trading, physical exercises, active travel, and private use [4-10]. Although Vietnam has a poor history of public space, modern society has been influenced by Western urban phenomena in constructing pseudo-public spaces [11]. Nevertheless, Vietnamese people often tend to use street space and its pavements as a public space for their leisure and daily activities [11]. In the context of the Vietnamese urban street, the difference of the two terms "public" and "private", described by Drummond (2000), is ignored. The boundary of using public and private space on the street is unclear and transgressed or blurred from "inside out" [11]. This means, individuals utilize street space for private activities 
that turn part of the public street space into their nominally private space [11]. This phenomenon is explained by Drummond (2000) in the description of Vietnamese social and cultural behaviors. Domestic scholars have further explained the use of street sidewalks as a living habit; the so-called "pavement culture" of the Vietnamese is closely tied to the concept of "economic pavement", both of which are distinctive characteristics of Vietnamese cities [12]. Over the years, streets and their pavements have been encroached upon for various purposes that affect traffic safety as pedestrians have to travel on roadways congested with motor vehicles. The street environment is also affected by litter. The chaotic status and irregular use of sidewalks for various purposes distort the urban visual view, affecting the streetscape and image of the city. To address the aforementioned problems, municipal authorities have upgraded street space by expanding road-widths, arranging street furniture, increasing pedestrian paths, and improving the quality and area of pavement, with the aim of making the street space tidy and more orderly. Also, the campaign namely "Taking pavements back to pedestrians" has been deployed to remove or curb/control private uses of street space and pavements.

\subsection{Previous Studies}

Perspectives of street space and pavements have turned those places intended by design for a purely traffic function into multifunctional spaces which then play a role as public places. Initially termed by Jacobs in the work namely "The death and life of American cities", street space was seen as public one [13]. Appleyard (1980) introduced plenty of concepts that considered a street as a community; as a place for lots of public activities for residents nearby and as neighborly territory [14]. In accordance with those perspectives, studies of Hoehner (2005), Mehta (2008), Mateo-Babiano (2007), and Espina (2018) aimed at impacts of street space and pavements on human beings, focusing on aspects like public health, and recreation [15-18]. Sociocultural cohesion was examined to produce some solutions for building, designing, and renovating better street space for citizens. In many Vietnamese cities, attempts by the government to upgrade and expand open street space are the most feasible for meeting the demands of inhabitants when faced with the scarcity of urban open space. The most recent attempts for the management of street space and pavements include banning private and trading activities encroaching on pavements; where the government expects to establish Western-like, modern, and neat urban space. This has become a matter of controversy among Vietnamese scholars. It is true that different users may perceive space in different ways [19]; to illustrate, for designers, visual quality is often the top priority in building open space, while this element is frequently underrated by users [1]. Besides research that proposed to design street space based on Western countries' experience, with the aim of building pedestrian-friendly street space and promoting social interaction [20], other studies put emphasis on the respect and preservation of street activities in Vietnam as part of cultural value and accepting such a multifunctional space as a feature of Vietnamese cities [11,12]. Research on the relationship between environment and user's behaviors helps to provide a sustainable and livable environment. With respect to Vietnamese street space, the research of Do (2018) identified factors that affect user's attention and established which physical elements should be prioritized in this space [21]. However, no study has yet focused on the relationship between environment and user's behaviors in this space. Moreover, no approach has been done to renovate street space based on how user's behaviors respond to street environment.

\subsection{Objective and Significance of Research}

Given methods of renovating and managing street space and pavements have aroused the controversy about how to build up environments for sustainable that matches the sociocultural context of Vietnam. Although some research suggested general solutions by referencing models of other countries, the most important design standard for a good living space is satisfying the demands of users [22], and each social class also affects the different use of the street space [23]. So, most importantly, it is necessary to research the relationship between user's activities and environmental factors in unimproved streets as this will become vital in designing, renovating, and establishing management 
methods of street space. This study seeks to discover Vietnamese behavioral characteristics and psychological needs in urban street space and associated pavements, and to understand the impact of street environment elements on users' behavior, so as to provide the foundation for improving quality and usability of street in the near future renovation and management.

\subsection{Unimproved and Improved Street Definitions}

The trend of movements toward multifunctional, pedestrian, and cycle-friendly streets can be found in the 1970s as described in the 1976 perspectives of Jane Jacobs in her work calling for a return to and eyes on the streets [24]. The street renovation was first introduced in the Netherlands under the Woonerf scheme that residential streets can be managed by inhabitants [25]. This renovation led to the interaction between traffic and commuters, but separating activities of pedestrians and cyclists from automobiles traffic [25]. Some woonerven projects have eliminated curbs, reduced traffic by using speed limits signs, modified infrastructure such as speed bumps, conducted street narrowing, and four-way stop signs that promoted social cohesiveness [25]. In the early 1990s, "Home zones" were made in the UK that share the street space between pedestrian and vehicle traffic [26]. The term of "Complete Streets" was initiated in the USA by Appleyard's research that has since recently inspired countries to aim at influencing physical and social activity by the means of street improvements. Therefore, street improvement initiatives aim at increasing street use of pedestrian and nonmotorized movement; also, streets are designed and managed to provide safe access for all users [27].

Following that trend, Vietnam's urban areas have begun to upgrade and renovate street space. Streets were actually built up in accordance with old standards of French or American colonial periods, in order to serve Vietnam wars and mainly function as means of commute. This previous intent of use does not meet the demands of modern cities with the high population density and resident's use of motor vehicles. Cities previously had lower population density; moreover, citizens rode bicycles and walked, so roads were narrow without any street furniture and simple pavements. The upgrading of Vietnam's street spaces included two main steps. The first stage is embellishing streets by such installation of amenities common elsewhere in the world, such as paving sidewalks, arranging signs, traffic lights, street lights, and drawing parking lines for pedestrian crossings (Figure 1). This stage is mostly complete for the urban streets of Vietnam. However, the second stage that focuses on expanding streets, pavements, enhancing pavement quality by using higher quality surfaces finishes, growing trees, arranging visual objects, benches, design trash bins, greeneries, and parking areas/lines; the banning or management of vendor trading/traditional private activities is a recent phenomenon and has been achieved in limited locations.

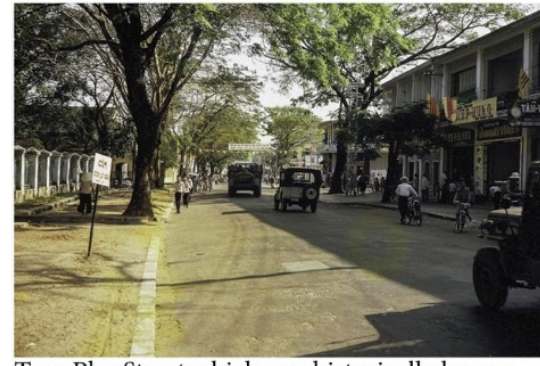

Tran Phu Street which was historically known as Doc Lap Street in 1965 consists of narrow pavement and narrow roadway with low quality. (Source: Bob Curry, Delta Company Mar 8, 1965 - Oct 1, 1965)

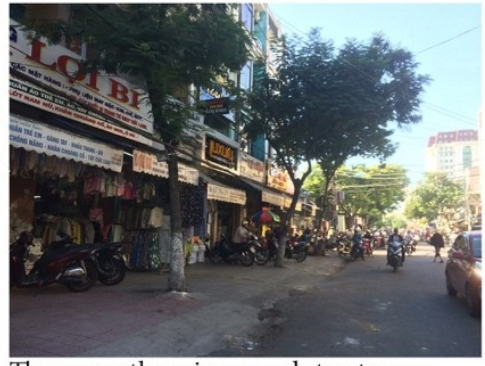

The currently unimproved street space (Tran Phu St.) does not have more changes than it was before, specifically narrow pavements and roadway.

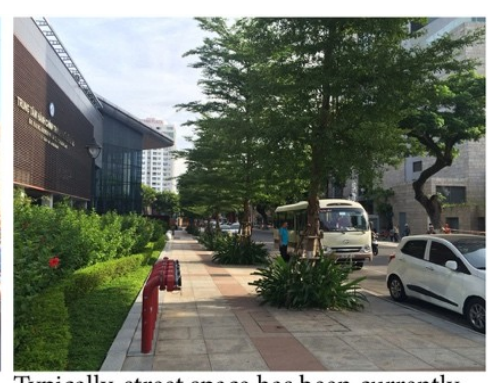

Typically, street space has been currently improved by widening pavements, enhancing quality, greening and so on.

Figure 1. Renovation situation of street space in Vietnam. 


\section{Materials and Methods}

\subsection{Research Area}

The two streets chosen for this research are Ong Ich Khiem Street and Tran Phu Street located in Da Nang city in Central Vietnam (Figure 2 and Table 1). This city was built up under the French colonial period and then became a military center in the war. After the 1980s, the city developed to become one of the three largest cities in Vietnam. The two mentioned streets were built pre-1980, and have since been embellished and used until now for a variety of activities and functions. In addition to commuting and travel, the streets are used for private and commercial function. Some of these functions have a negative impact on the street space. Indeed, although those streets have yet to be renovated with poor quality and physical settings, many activities have encroached pavements and roadway exerted series of mutually negative impacts in such space. These are suitable places for research on good features of the relationship between human activities and the environment in old streets.

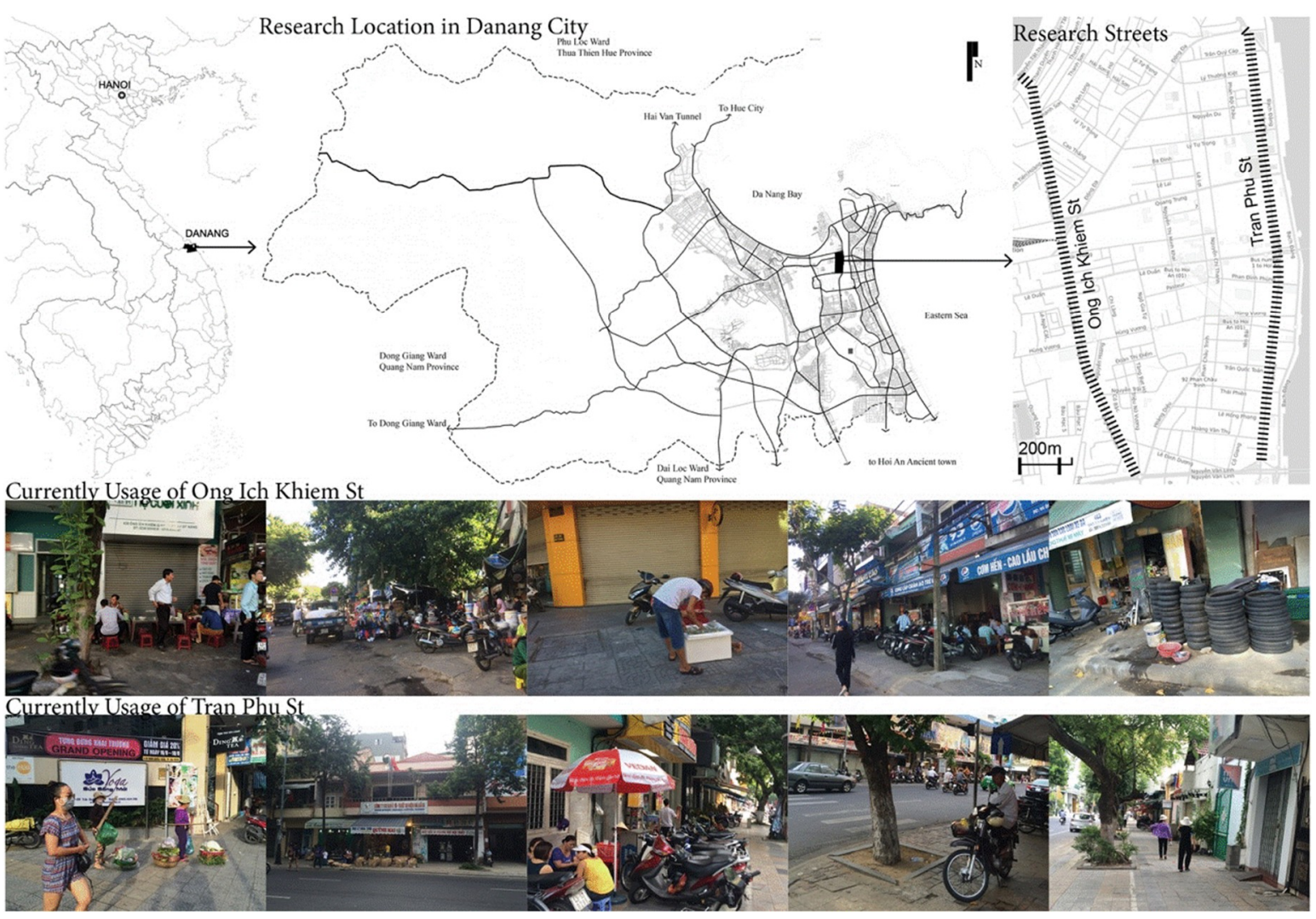

Figure 2. Street space samples location and current situation.

Table 1. Street space samples overview.

\begin{tabular}{ccc}
\hline Street Name & Ong Ich Khiem & Tran Phu \\
\hline Street Type & Collector Streets & Collector Streets \\
\hline Length & $2.22 \mathrm{~km}$ & $2.3 \mathrm{~km}$ \\
\hline Width & $10.5 \mathrm{~m}$ & $10.5 \mathrm{~m}$ \\
\hline Pavement Width & $1-4 \mathrm{~m}$ & $4-6 \mathrm{~m}$ \\
\hline Land use along the street & $\begin{array}{c}\text { Residences, Commercial Buildings, } \\
\text { Administration Agency, Public building }\end{array}$ & $\begin{array}{c}\text { Residences, Commercial Buildings, } \\
\text { Adreenspace, Markets, School, Shop house, } \\
\text { Administration Agency, Public building }\end{array}$ \\
\hline Setback & $1.2 \mathrm{~m}$ & $1.2 \mathrm{~m}$ \\
\hline
\end{tabular}




\subsection{Outline of Investigation}

To avoid bias and in an attempt to obtain a complete list of all activities along the streets, observations were conducted for three different time frames including morning ( $6 \mathrm{am}-9 \mathrm{am}$ ), noon (11 am-2 pm), and afternoon (4 pm-7 pm) on two weekdays and two weekends. The observations included two stages: firstly, the investigation of current structures and kinds of physical settings that the streets contained was carried out and reported and secondly, all user's street activities were recorded on the paper-based maps based on place-centered behavioral mapping (PcBM) and visual encounter surveys (VES). The place-centered behavioral mapping (PcBM) is used to make a graphical representation of the study location, dividing into different segments. The observation contains photographs or time-lapse recordings of behaviors and positions of people in each segment. This type of observation is considered more suitable for the study of a particular physical space [28]. Visual Encounter Survey (VES) method is used to document the presence of individuals, and it can provide both quantitative and qualitative data and were formalized by Campbell \& Christman (1982) [29]. It was conducted by observers walking through a designated area for a prescribed time, visually investigating the required objects. The physical environment investigation was conducted on May 4th (Friday) and May 5th (Saturday) using the VES method which requires observers to walk along the street to collect all data regarding current situation of street environment such as physical setting, audio, and scent (Figure 3). User's activities were collected by PcBM on two weekend days and two weekdays; May 12th (Saturday), May 19th (Saturday), May 15th (Tuesday), and May 17th (Thursday) that record all users' activities in physical, social, and stationary terms. Participants in one certain activity were considered as an activity unit (Figure 3).
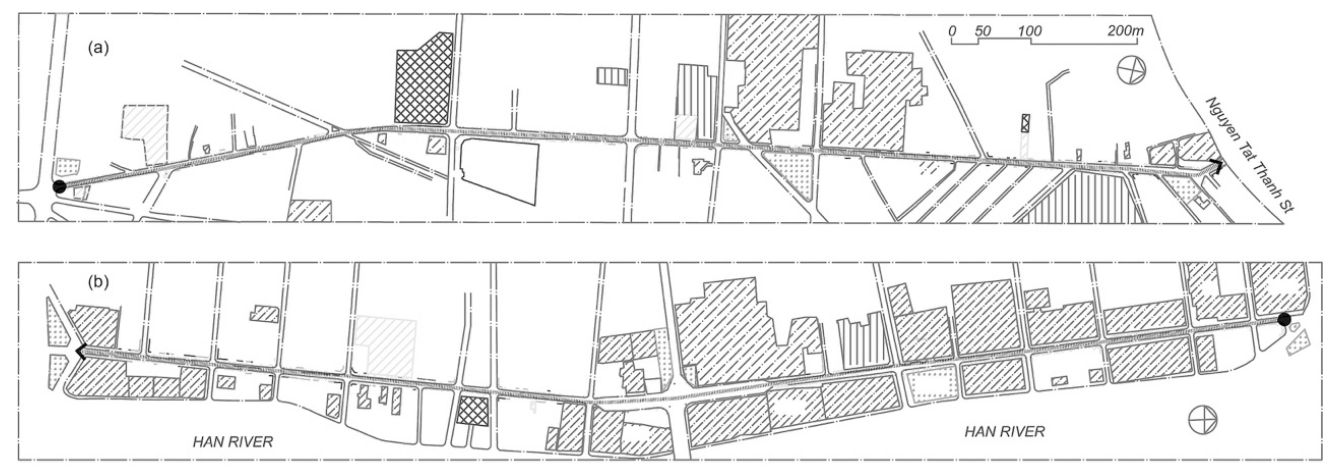

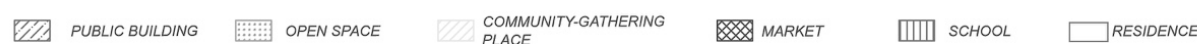

Figure 3. Investigation route in two street spaces: (a) investigation path on Ong Ich Khiem St and (b) investigation path on Tran Phu St.

\subsection{Definition of Users' Behaviors and Their Categories}

Users' behaviors were defined based on their action/activities within personal environment and then classified into behavior categories according to behavior settings, which are ecological units where the physical environment and the behavior are indissolubly connected [30-32]. Based on investigation data (i.e., photos and video records), all typical user's behaviors were collected. Due to the huge quantity and variety of activities on streets and pavements, user's behaviors, before classification, would be thoroughly observed and common behavior settings that present in the street space would be carefully created and denominated to describe the purposes of relevant activities to the surrounding environment based on the theory of proxemics proposed by Edward T. Hall [33] (Figure 4). 


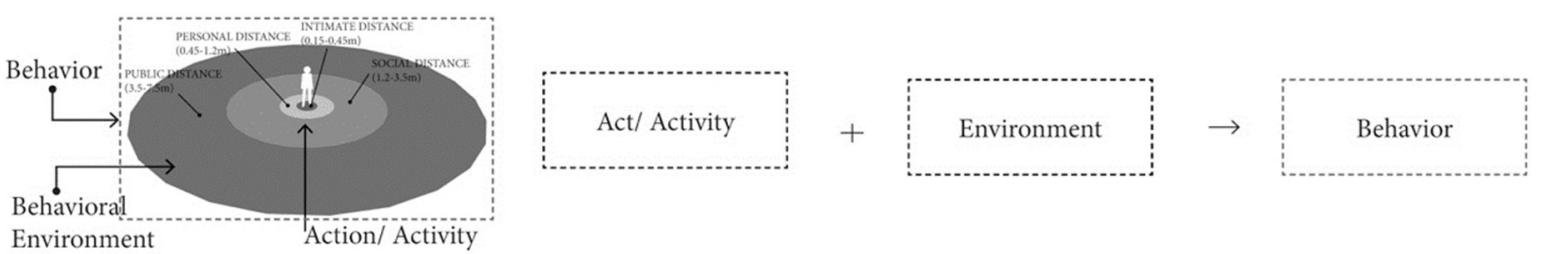

Figure 4. Schematic representation of user's behavior definition.

\subsection{Division of Street Segments}

According to street space characteristics and behavior setting concepts mentioned in the last section, the street environment and user's behaviors can be divided into sections (Figure 5). Section A, which describes the space where two or more streets intersect (excluding small alleys as they do not attract no motorized traffic movement), has potential in various traffic movements. Intersections of both streets-Ong Ich Khiem Street and Tran Phu Street-were defined as Section A and A7 respectively. Section B refers to segments where houses are on both sides of the street and they were named B and B' for these spaces in Ong Ich Khiem Street and Tran Phu Street, respectively. The typical sections of each type are illustrated in Figure 6.

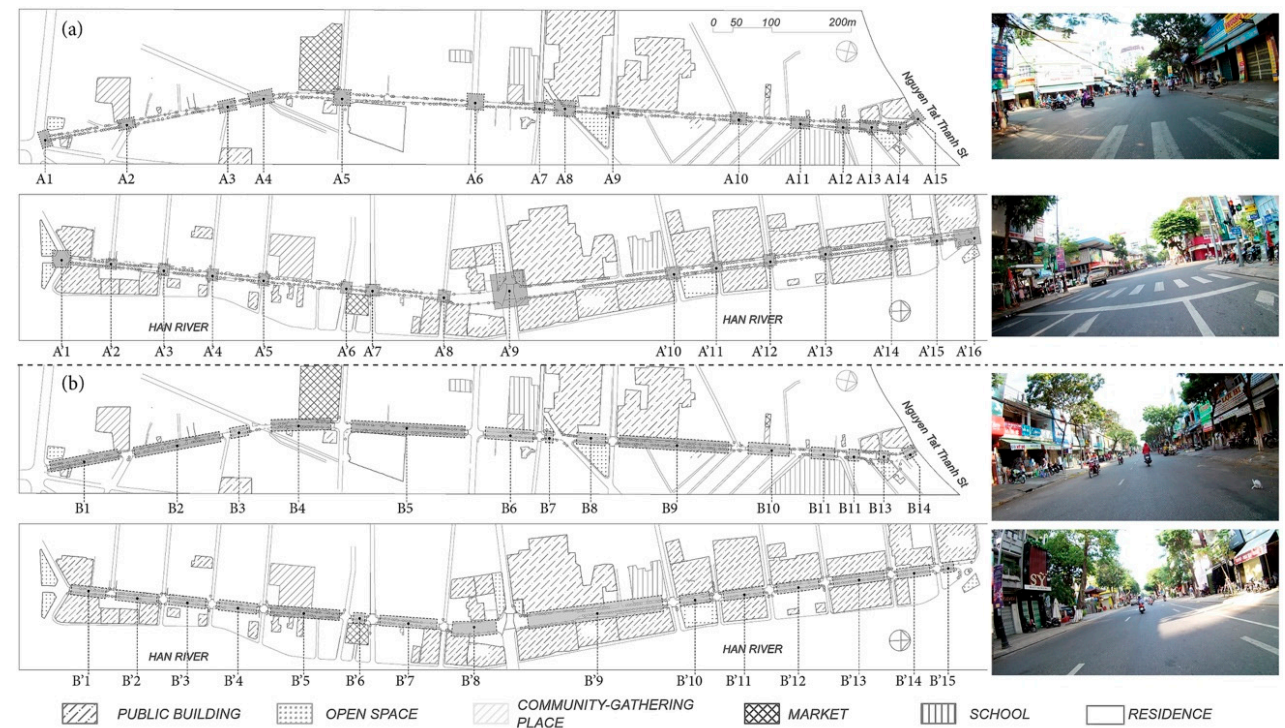

Figure 5. Street sections division: (a) A sections-intersection spaces; (b) B sections (middle street segment)—unit front houses on both sides.

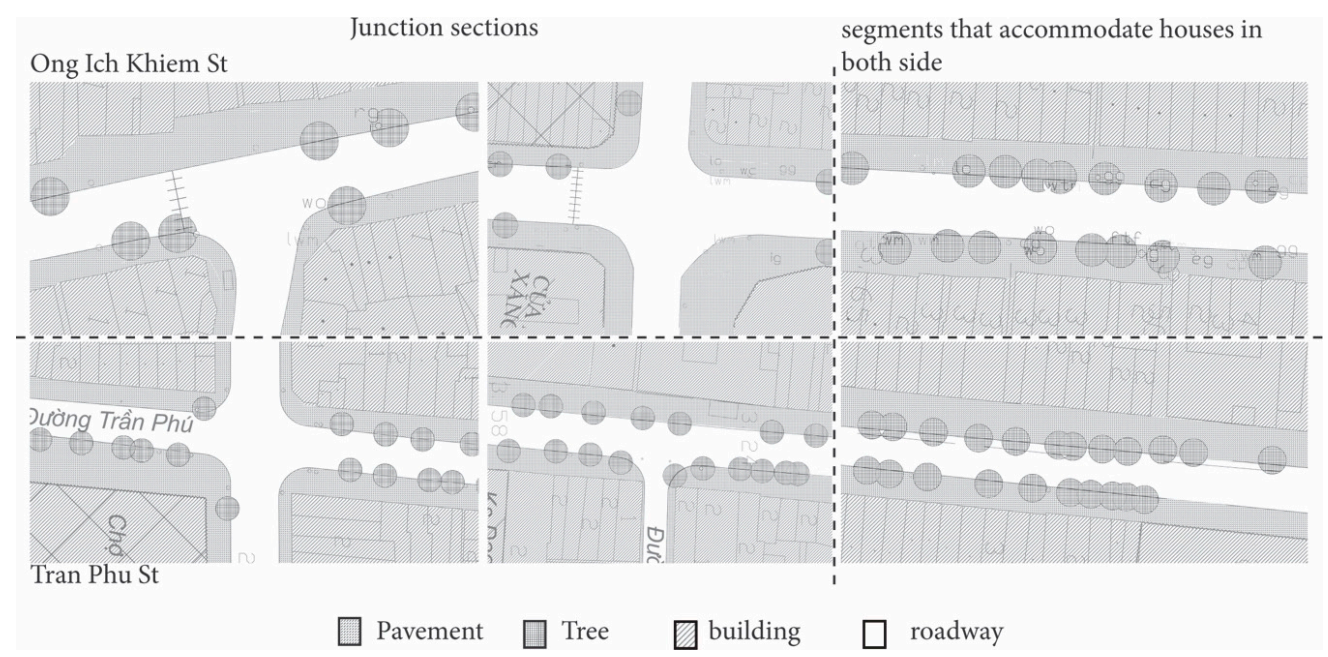

Figure 6. Typical space structure of both kinds of sections in two streets. 


\section{Results}

\subsection{Users' Behavior}

All users' behaviors were collected and described, and the descriptions were classified into six categories and 26 subgroups (Figure 7). The first group refers to the accessibility by users. This category describes the act of walking to a destination or arriving and departing that place by motor vehicle. This behavior group consists of four types. The first one is "crossing road" which happens when being allowed to or not, residents cross the street when needed. The second one is "walking for destination" and refers to the act of walking along the street on sidewalks and street. In the social context of Vietnam, pavements are often occupied for the personal purposes of residents, therefore pedestrians have to travel on the street. The third and fourth types are called "coming/leaving with motorcycle/without motorcycle", which describe the act that residents plan to leave pavements to participate in mainstream traffic on roads, or to approach certain areas of pavements from mainstream traffic on roads.

The second kind of users' behavior regarding trading activities includes four medium types. Firstly, "fixed food transaction place" is primarily a fixed location food vendor that operates from the pavement area. The second type is similar to the first one, but conduct mobile food trading along pavements or roadsides, or what is commonly known as street vending. The two remaining types are similar, describing the trading of such goods as consumer goods or unprocessed food.

The third category is about idling behaviors like standing and waiting for something. This type is divided into four subcategories: firstly, "waiting before crossing road" details the act of waiting for a red traffic light in intersections before crossing roads. Secondly, "waiting for others" describes the act of temporarily parking motorbikes at the roadside or on pavements to wait for relatives buying something or doing something in a short time. Thirdly, "waiting for the bus" often occurs at bus stops. Finally, "waiting for the customers" refers to the long-term wait, which often occurs on pavements where motorbike drivers wait for new guests.

The fourth category that describes behaviors of service/maintenance consists of five subcategories. The first group mentions "cleaning" activities, which, as the name states, mentions the act that residents clean pavements in front of their houses or shophouses. Meanwhile, "commercial preparation" refers to activities of arranging and displaying goods for sale, which often take place on pavements. "Guarding" is named for the activity of those getting chairs outside shops on pavements and observing or supporting customers, concurrently keeping motorcycles away from thefts in some stores or banks. Environmental staff members take care of plants along streets or collect litter and are classified in the category of "public maintenance". Finally, the act of "repairing" occurs on pavements to serve needs of repairing vehicles, making keys, and other amenities.

The fifth classification of user's behaviors is regarded as for relaxation that can be divided into 6 smaller groups. "Playing" refers to children-related activities and occurs on pavements or on the roadside. "Reading" includes reading newspapers, books, or other information on electronic devices; these activities often occur on pavements. The act of "strolling", both of citizens and travelers, often takes place on both pavements and roadsides and they regularly go for a walk to sightsee and enjoy the urban atmosphere or simply escaping from cramped spaces of roll houses. On pavements right in front of house doors, people often lean back on their chairs, do nothing and watch the world go by, which is seen as a means of relaxation and denominated as "looking others". "Resting" refers to relaxing activities occurring on pavements as taking naps on chairs, motorbikes, or taxis. The final one is the act of gathering to "chat" on pavements, or even in roadsides.

The last group can be called as "others" that mentions three subgroups. The first one indicates "inquiring" behavior that can be seen when people stand on roadsides and quickly asking/ communicating with others for something. The two remaining behaviors are related to "eating" and "drinking" that occur on pavements occupied by food or beverage vendors. People sit on chairs with tables in front of them. 


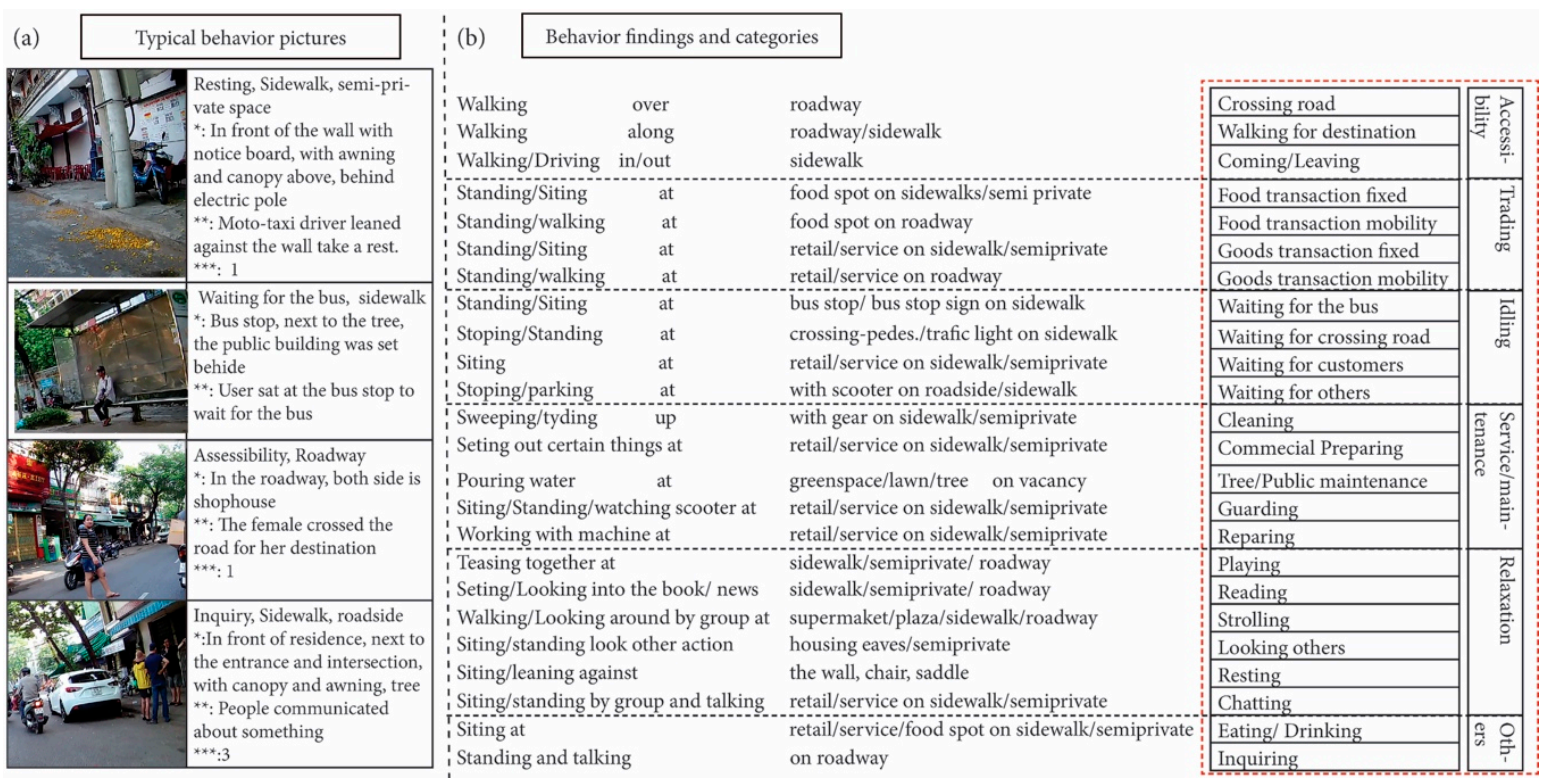

Figure 7. Summary of users' behaviors along streets and its pavements: (a) identifying behaviors samples and (b) behavior setting and its categories.

\subsection{Statistics of Users' Behavior}

Within four survey days, the frequency of behavior units appearing on both streets was 3636 times. On the basis of the behavior category mentioned in Section 3.1, the occurrence frequency of users' behaviors on each group is shown in Table 2. The behavior group as "Accessibility" occurred the most frequently and could be considered as the dominant behavior on two streets (recorded 1287 times). The subdivision of "accessibility", "leaving/coming with motorcycle", was treated as the behavior with the highest frequency of 626 times compared with others on the street. Three kinds of behaviors as "walking for destination", "waiting for others", and "looking at others" came the second in the same street with the reported frequency of 331 times, 314 times, and 302 times, respectively.

The sections with the highest frequency of behaviors in two streets were revealed in Figure 8. Most noticeably, those sections emerged in middle street segments that accommodate residents with row houses in both sides as B1, B2, B4, B5, B9, and B'5 recording 242, 239, 230, 505, 232, and 231 times, respectively (the overall average behavior frequency is 60.6 times). By contrast, in some junctions, the frequency of human behaviors was low (below average), only Section A'7 was recorded with nearly average frequency of 61 times.

Meanwhile, the diversity of behaviors appearing in all sections of both streets were found on Sections B4 and B5 with 25 or more kinds of behaviors; B1, B2, B6, B8, B'2, B'5, and B'7 with over 20 kinds of behaviors; and A2, B3, A4, A8, B10, B11, B'4, A'7, B'9, and B'13 with over 15 kinds of behaviors. The remaining sections had the nearly average or lower frequency, which refers to the poverty of human activities in this space, most noticeably as $\mathrm{A}^{\prime} 15, \mathrm{~B}^{\prime} 15, \mathrm{~A}^{\prime} 10$, and $\mathrm{A}^{\prime} 1$. 
Table 2. Occurrence frequency of users' behavior.

\begin{tabular}{|c|c|c|c|c|}
\hline $\begin{array}{l}\text { Behavioral } \\
\text { Category }\end{array}$ & Specific Behaviors & $\begin{array}{c}\text { Behavior } \\
\text { Frequency in Ong } \\
\text { Ich Khiem St }\end{array}$ & $\begin{array}{c}\text { Behavior } \\
\text { Frequency in } \\
\text { Tran Phu St }\end{array}$ & Total \\
\hline \multirow{4}{*}{ Accessibility } & crossing road & 62 & 48 & 110 \\
\hline & leaving/coming with motorcycle & 421 & 205 & 626 \\
\hline & leaving/coming without motorcycle & 146 & 74 & 220 \\
\hline & walking for destination & 204 & 127 & 331 \\
\hline \multirow{4}{*}{ Trading } & food transaction fixed & 66 & 8 & 74 \\
\hline & goods transaction fixed & 25 & 2 & 27 \\
\hline & food transaction mobility & 78 & 4 & 82 \\
\hline & goods transaction mobility & 51 & 21 & 72 \\
\hline \multirow{4}{*}{ Idling } & waiting for crossing road & 46 & 24 & 70 \\
\hline & waiting for others & 225 & 89 & 314 \\
\hline & waiting for the bus & 4 & 11 & 15 \\
\hline & waiting for customers & 70 & 55 & 125 \\
\hline \multirow{5}{*}{$\begin{array}{c}\text { Service/ } \\
\text { Maintenance }\end{array}$} & cleaning & 73 & 23 & 96 \\
\hline & commercial preparation & 57 & 16 & 73 \\
\hline & guarding & 46 & 111 & 157 \\
\hline & public maintenance & 20 & 17 & 37 \\
\hline & repairing & 51 & 8 & 59 \\
\hline \multirow{6}{*}{ Relaxation } & playing & 21 & 9 & 30 \\
\hline & reading & 75 & 36 & 111 \\
\hline & strolling & 72 & 117 & 189 \\
\hline & looking others & 210 & 92 & 302 \\
\hline & resting & 29 & 29 & 58 \\
\hline & chatting & 50 & 32 & 82 \\
\hline \multirow{3}{*}{ Others } & eating & 89 & 9 & 98 \\
\hline & inquiring & 76 & 34 & 110 \\
\hline & drinking & 122 & 46 & 168 \\
\hline
\end{tabular}

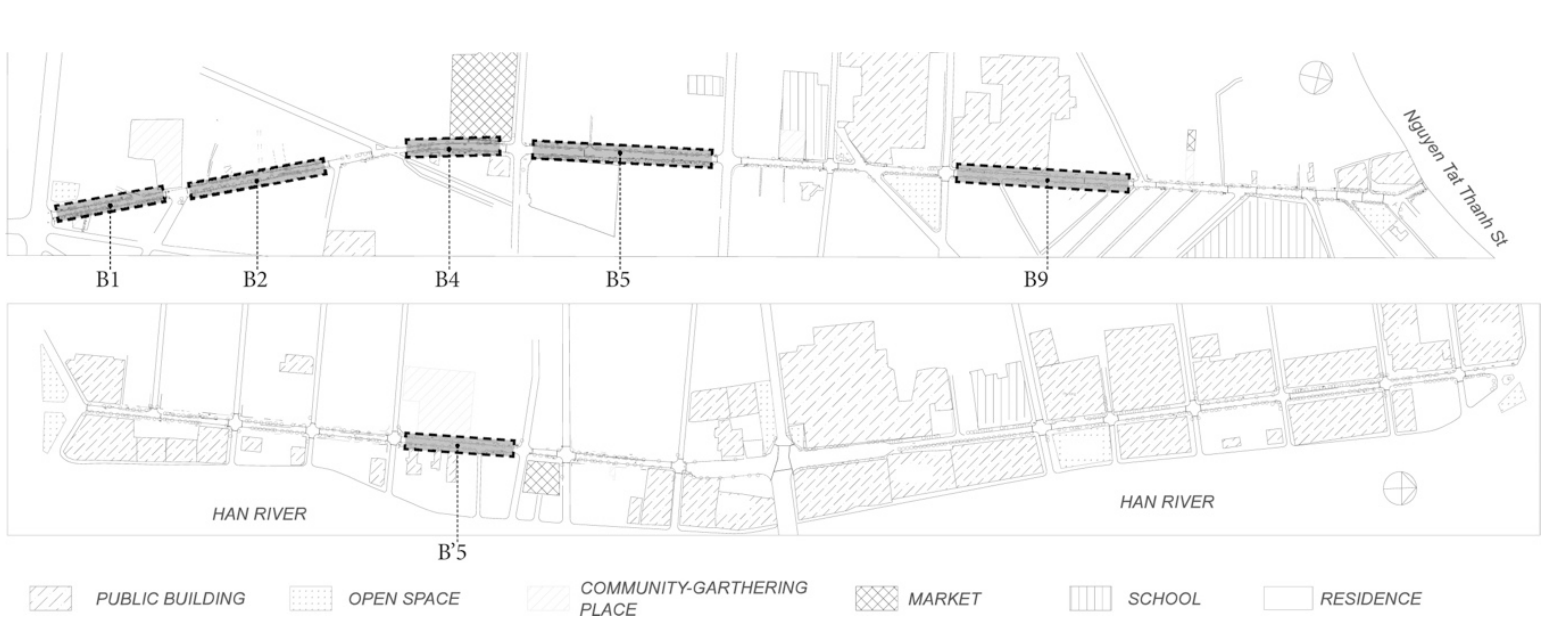

Figure 8. The sections with high occurrence frequency of behavior in two streets.

\subsection{Behavior Analysis According to Physical Environment Classification}

User's behaviors and street environments were further analyzed using principal component analysis (PCA) and cluster analysis (CA) to reveal the distribution of user's behaviors related to physical environment features along the streets.

\subsubsection{Classification of Environmental Characteristics of Street Space}

Data related to physical environment features around streets and their pavements were collected and tabulated in Table 3, denoted by " 1 " and " 0 " for their presence and absence, respectively. The characteristics of street environment were processed by PCA via Xlstat statistical software add-in of Microsoft Excel. 
The analysis results show that the cumulative contribution rate is $67.1 \%$ explained in the 1 st to 4th axis as shown in Table 4.

On the first axis (F1), the negative eigenvalues indicate the feature of offices/public agency, vacancies, greenspace, curb cuts, fire hydrants, and unofficial signs, while the significant positive eigenvalues indicate the feature of retail \& service, food spots, residence, awning, balcony, and store sign. Therefore, the 1st axis stands for Multifunctional usage and Vision of street space.

On the second axis (F2), the significant negative eigenvalues point out the features of sidewalk width of over $6 \mathrm{~m}$ (TP)/over $4 \mathrm{~m}$ (OIK), trashcans, motorcycle parking lines, and official signs, while the significant positive eigenvalues marks the features of Street width of over $10.5 \mathrm{~m}$ out. Therefore, the 2nd axis stands for Walkable and Navigation of space.

The significant positive eigenvalues on the third axis (F3) indicate recreational facilities, car parking area, and crossing pedestrian. Therefore, the 3rd axis stands for facilities of street

Finally, on the fourth column (F4), the significant positive eigenvalues indicate the feature of fence and sign poles, while the significant negative eigenvalues aim to electric poles/infra. Hence, the 4th axis is for The Obstruction.

To some extent, four axes may explain all qualities and features of street spaces in this study. Using the environment characteristic data distributed within 60 sections to perform the cluster analysis, the sections can be classified into 12 groups (Figures 9 and 10).

Table 3. Characteristics of physical environment in streets.

\begin{tabular}{|c|c|c|c|c|c|c|c|c|c|c|c|c|c|c|c|c|c|c|c|c|c|c|c|c|c|}
\hline \multirow{3}{*}{ 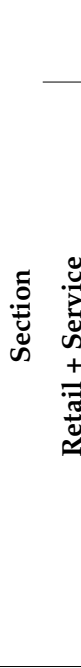 } & \multicolumn{6}{|c|}{$\begin{array}{l}\text { Commercial/Private } \\
\text { Component }\end{array}$} & \multicolumn{12}{|c|}{ Public Component } & \multicolumn{7}{|c|}{$\begin{array}{l}\text { Street Functions } \\
\text { Component }\end{array}$} \\
\hline & & $\stackrel{\mathscr{D}}{=}$ & 仓ેّ & & & & 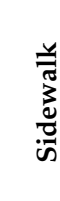 & & 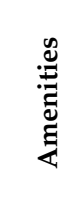 & & & 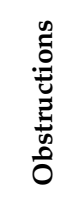 & مُ & & & 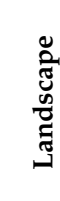 & & & $\begin{array}{l}5 \\
3 \\
3\end{array}$ & & $\underset{\omega}{\infty}$ & & & 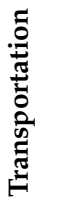 & \\
\hline & w & 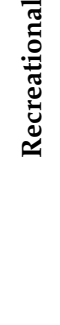 & 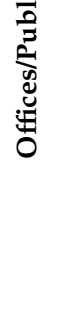 & 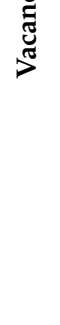 & 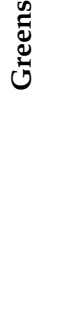 & 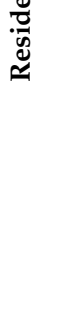 & 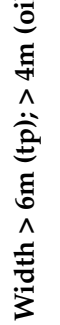 & 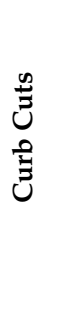 & 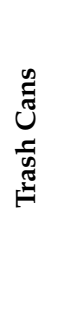 & 芯 & 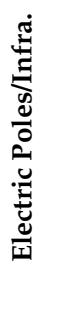 & 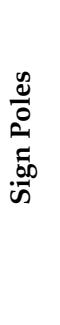 & 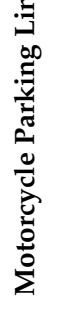 & 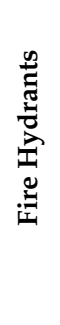 & $\stackrel{\mathscr{\Xi}}{\rightleftarrows}$ & 岂 & 总 & 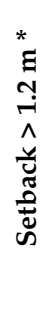 & 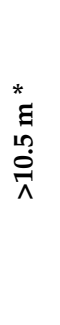 & 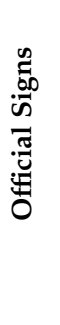 & 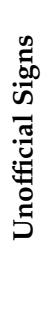 & 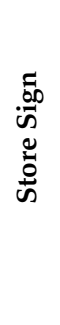 & 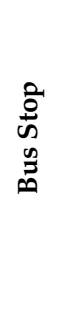 & 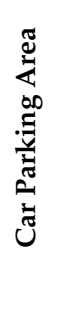 & 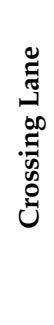 \\
\hline A1 1 & 0 & 0 & 0 & 0 & 0 & 0 & 1 & 1 & 0 & 1 & 1 & 1 & 0 & 0 & 1 & 1 & 0 & 0 & 1 & 1 & 0 & 1 & 0 & 0 & 1 \\
\hline B1 1 & 1 & 0 & 0 & 0 & 0 & 1 & 0 & 1 & 0 & 0 & 1 & 0 & 0 & 0 & 1 & 1 & 1 & 0 & 0 & 1 & 1 & 1 & 0 & 0 & 0 \\
\hline$\ldots \ldots$ & . $\ldots$ & $\ldots$ & $\ldots$ & $\ldots$ & $\ldots$ & $\ldots$ & $\ldots$ & $\ldots$ & $\ldots$ & $\ldots$ & $\ldots$ & $\ldots$ & $\ldots$ & $\ldots$ & $\ldots$ & $\ldots$ & $\ldots$ & $\ldots$ & $\ldots$ & $\ldots$ & $\ldots$ & $\ldots$ & $\ldots$ & $\ldots$ & $\ldots$ \\
\hline B14 1 & 0 & 0 & 1 & 0 & 0 & 1 & 0 & 1 & 0 & 1 & 1 & 0 & 0 & 0 & 0 & 0 & 0 & 1 & 1 & 1 & 1 & 1 & 0 & 0 & 0 \\
\hline A151 & 1 & 0 & 1 & 0 & 0 & 0 & 0 & 1 & 0 & 1 & 0 & 1 & 0 & 0 & 1 & 1 & 0 & 1 & 1 & 0 & 1 & 0 & 0 & 0 & 1 \\
\hline $\mathrm{A}^{\prime} 10$ & 0 & 0 & 0 & 1 & 1 & 0 & 1 & 1 & 0 & 1 & 1 & 1 & 0 & 0 & 1 & 0 & 0 & 1 & 0 & 1 & 1 & 0 & 1 & 0 & 1 \\
\hline B'1 $1^{\prime}$ & 0 & 0 & 1 & 0 & 0 & 1 & 1 & 2 & 1 & 1 & 1 & 0 & 1 & 0 & 1 & 1 & 1 & 1 & 0 & 1 & 1 & 1 & 0 & 0 & 0 \\
\hline$\ldots \ldots$ & . $\ldots$ & $\ldots$ & $\ldots$ & $\ldots$ & $\ldots$ & $\ldots$ & $\ldots$ & $\ldots$ & $\ldots$ & $\ldots$ & $\ldots$ & $\ldots$ & $\ldots$ & $\ldots$ & $\ldots$ & $\ldots$ & $\ldots$ & $\ldots$ & $\ldots$ & $\ldots$ & $\ldots$ & $\ldots$ & $\ldots$ & $\ldots$ & $\ldots$ \\
\hline B'151 & 0 & 0 & 1 & 1 & 0 & 0 & 1 & 1 & 0 & 1 & 1 & 0 & 1 & 0 & 1 & 0 & 0 & 1 & 0 & 1 & 1 & 1 & 0 & 0 & $\overline{0}$ \\
\hline$A^{\prime} 160$ & 0 & 0 & 1 & 0 & 1 & 0 & 1 & 1 & 0 & 1 & 1 & 0 & 0 & 0 & 1 & 0 & 0 & 1 & 1 & 1 & 1 & 0 & 0 & 0 & 0 \\
\hline
\end{tabular}


Table 4. Score of categories of physical environment in streets.

\begin{tabular}{|c|c|c|c|c|}
\hline & F1 & F2 & F3 & F4 \\
\hline Retail + Service & 0.849 & 0.001 & -0.064 & 0.201 \\
\hline Food Spots & 0.445 & -0.119 & 0.217 & 0.033 \\
\hline Recreational Facilities & -0.410 & 0.160 & 0.457 & 0.054 \\
\hline Offices/Public Agency & -0.498 & 0.030 & -0.492 & 0.092 \\
\hline Vacancies & -0.366 & -0.106 & 0.215 & -0.068 \\
\hline Greenspace & -0.482 & 0.378 & 0.161 & -0.060 \\
\hline Residence & 0.829 & -0.111 & 0.174 & -0.040 \\
\hline Sidewalk Width $>6 \mathrm{~m}$ (TP); >4 m (OIK) & -0.463 & -0.547 & -0.073 & 0.237 \\
\hline Curb Cuts & -0.451 & -0.276 & -0.227 & 0.298 \\
\hline Trash Cans & 0.082 & -0.525 & -0.148 & 0.231 \\
\hline Fence & -0.172 & 0.020 & 0.045 & 0.473 \\
\hline Electric Poles/Infra & -0.088 & -0.014 & -0.033 & -0.450 \\
\hline Sign Poles & -0.091 & -0.241 & 0.265 & 0.502 \\
\hline Motorcycle Parking Line & -0.207 & -0.703 & -0.157 & -0.018 \\
\hline Fire Hydrants & -0.487 & -0.160 & 0.426 & -0.175 \\
\hline Trees & 0.012 & -0.176 & 0.269 & 0.026 \\
\hline Awning & 0.659 & -0.136 & 0.112 & -0.077 \\
\hline Balcony & 0.560 & -0.394 & 0.150 & -0.255 \\
\hline Setback $>1.2 \mathrm{~m}$ & -0.384 & 0.178 & -0.062 & -0.072 \\
\hline Street Width $>10.5 \mathrm{~m}$ & -0.066 & 0.580 & -0.143 & 0.168 \\
\hline Official Signs & -0.108 & -0.529 & -0.098 & -0.255 \\
\hline Unofficial Signs & -0.350 & -0.196 & -0.236 & -0.301 \\
\hline Store Sign & 0.852 & 0.018 & 0.035 & 0.007 \\
\hline Bus Stop & -0.221 & 0.052 & 0.058 & -0.104 \\
\hline Car Parking Area & -0.535 & -0.148 & 0.649 & -0.150 \\
\hline Crossing Lane & 0.071 & -0.001 & 0.504 & 0.291 \\
\hline Eigenvalue & 23.320 & 9.046 & 4.673 & 3.202 \\
\hline Variability (\%) & 38.867 & 15.077 & 7.788 & 5.337 \\
\hline Cumulative (\%) & 38.867 & 53.944 & 61.732 & 67.069 \\
\hline
\end{tabular}

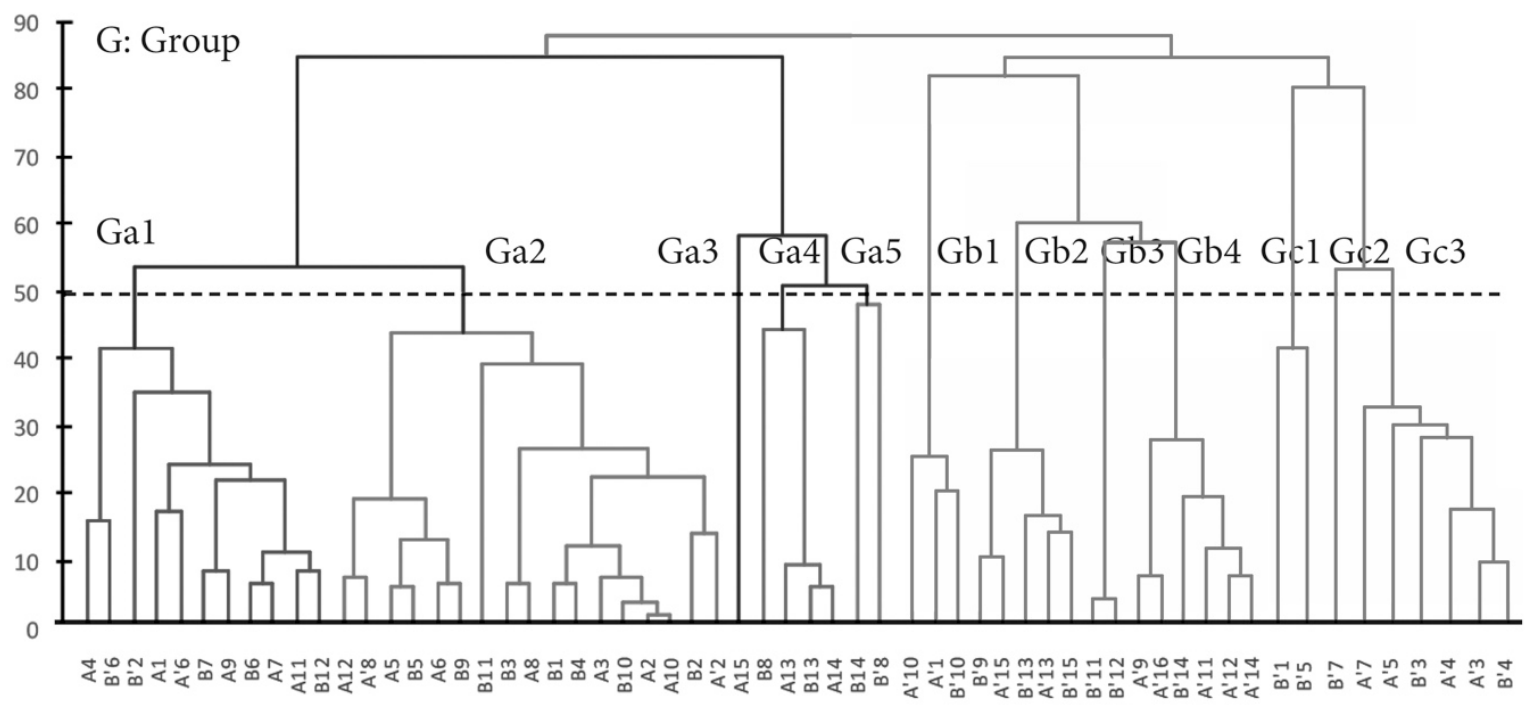

Figure 9. Section classification using cluster analysis. 


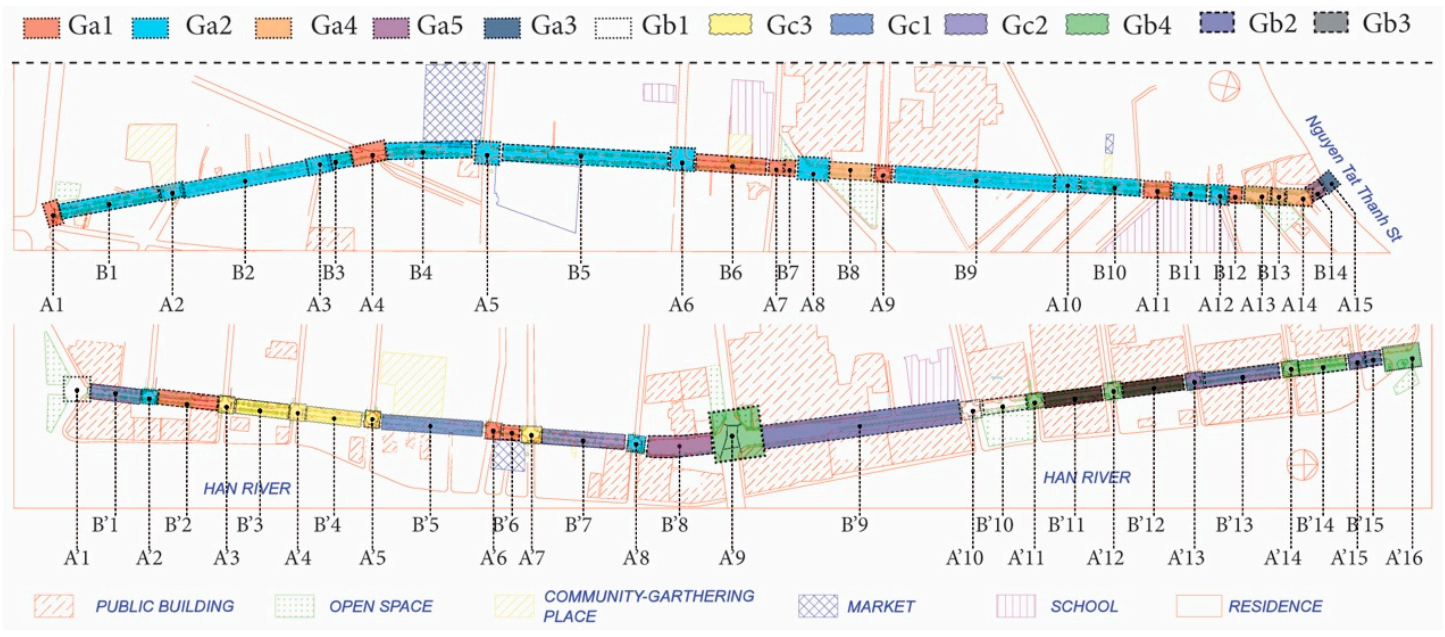

Figure 10. The distribution of sections in relation to 12 groups of environment space.

\subsubsection{Distribution of User' Behaviors According to Different Groups of Street Space}

User's behaviors along the street (60 sections) are categorized into six behavioral categories including 26 specific behaviors; the average frequency of each behavior category in these sections is commonly reasoned as $\sim 7 \%$, hence the number of occurrences (over $7 \%$ ) is considered as "high". If the occurrence frequency of a certain behavior is over $7 \%$ in more than half of the sections, when focusing on one group of street space, the behavior in this group will be defined as "frequent". With the same rule, if the frequency of a certain behavior is under $7 \%$ in all sections, when focusing on one group of street space, this behavior will be treated as "infrequent".

Group Gc2 and Ga2 attracted the most users' behaviors with high frequency in such behavioral categories as Accessibility or Trading, Service/Maintenance, Relaxation, and Others which includes the subgroups of crossing road, leaving/coming with motorcycle, leaving/coming without motorcycle, walking to destination, goods transaction mobility, cleaning, guarding, playing, reading, strolling, looking others, resting, and drinking coffee. Meanwhile, Groups Gb1 and Ga3 were seen to discourage most human activities. Ga2 was observed to record neither highly frequent behaviors nor lowly frequent activities (Figure 11).

In short, analysis results indicate that the distribution of 26 specific behaviors is uneven in different group spaces. Also, it can be categorized into three typical environmental behavior types that represent characteristics of each space for relevant physical settings (Figure 12).

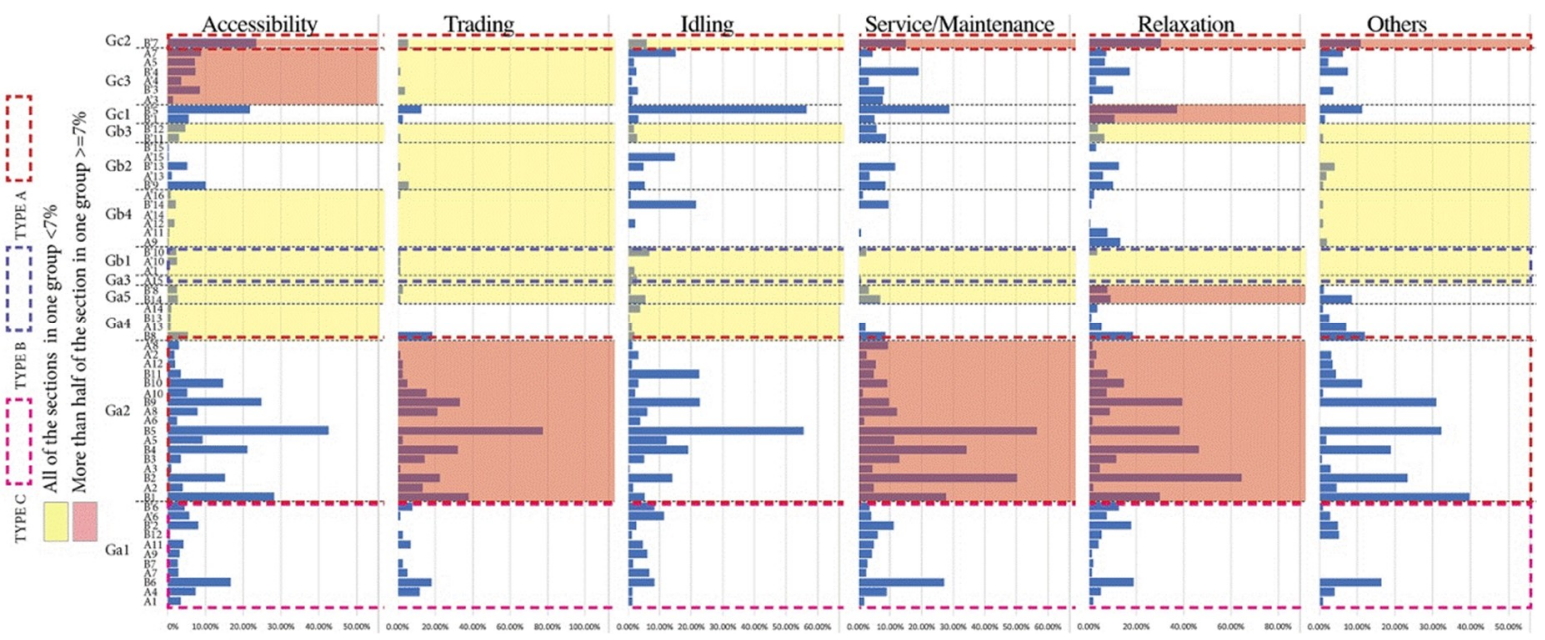

Figure 11. Distribution of users' behaviors in the 12 groups of space. 


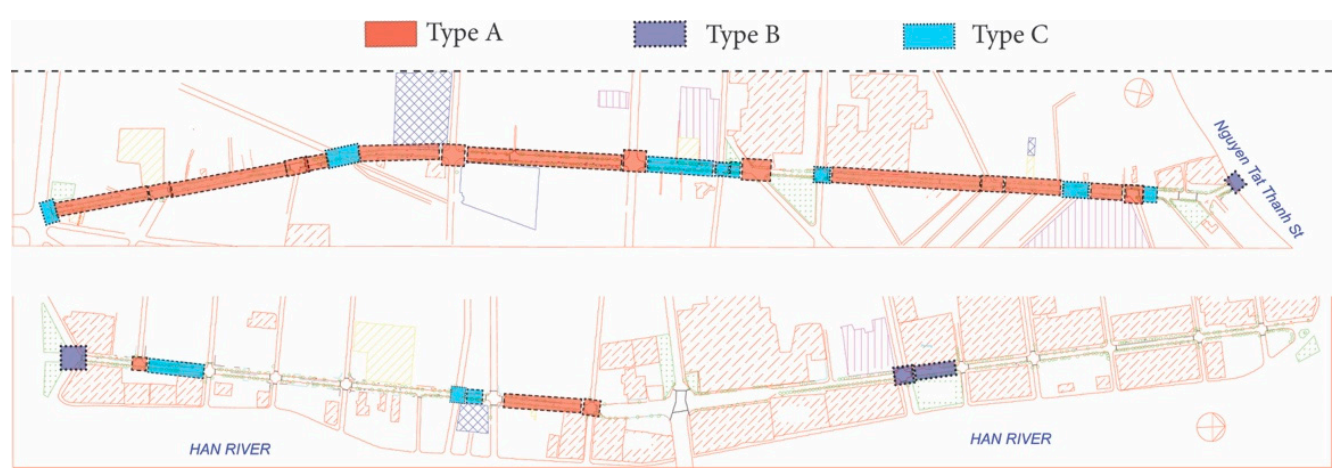

Figure 12. The distribution of three typical behavioral environment types in street space.

\section{Discussion}

4.1. Discussion of Relationship between Users' Behaviors and the Physical Environment on Three Typical Environmental Behavior Patterns on Street Space

(1) In Type A, in which various frequent behaviors occurred and consisted of necessary/optional/social activities such as accessibility, trading, service/maintenance, relaxation, and other (Figures 11 and 13), the findings are as follows.

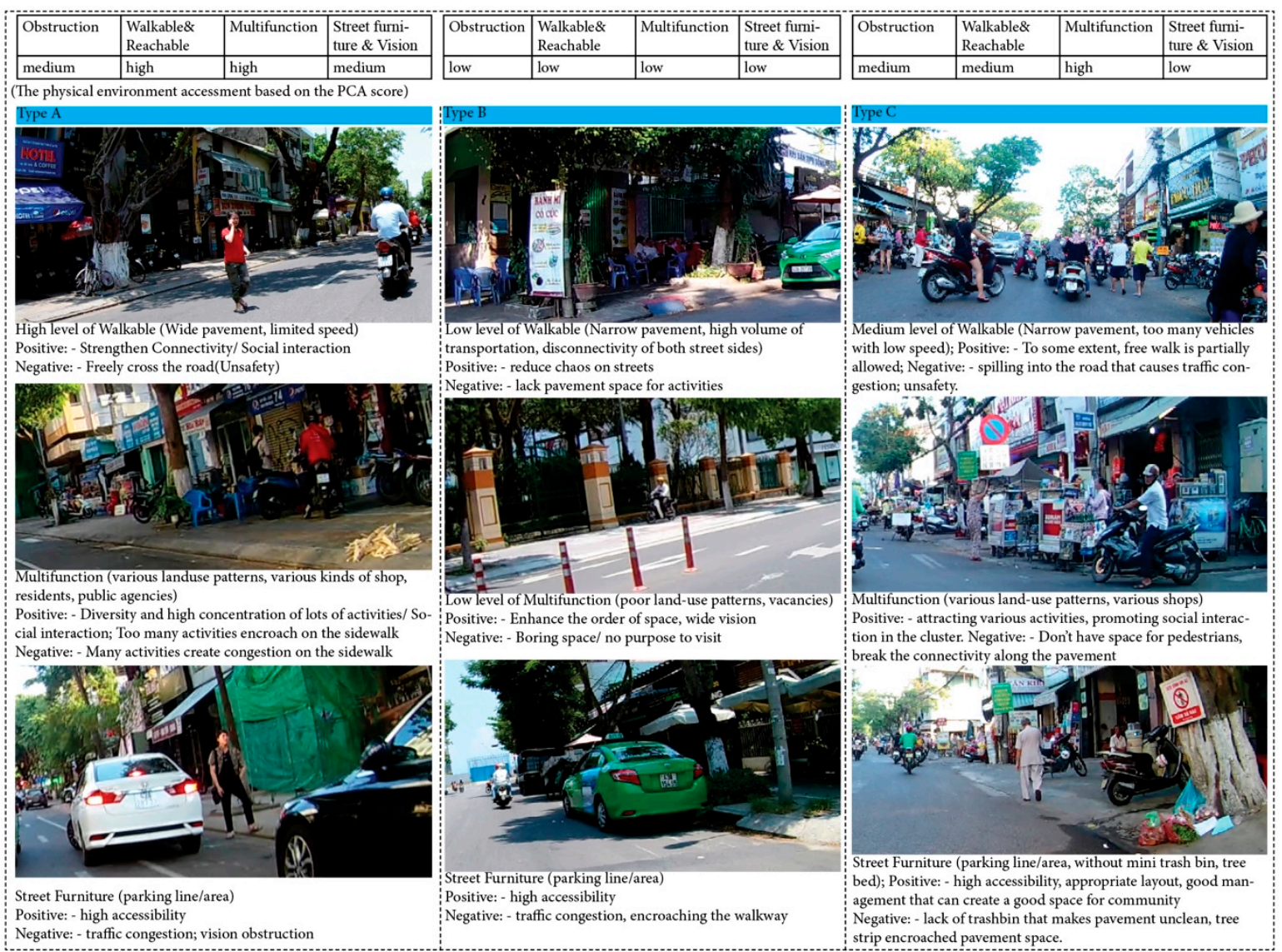

Figure 13. Characteristics of three typical types of environmental behaviors. 
Positive aspects: High level of walkable \& accessible areas that benefited/arose from having a wide pavement, setback/balcony, curb cuts, and limited speed; these factors can provide space for various behaviors to strengthen connectivity and social interaction. The multifunction uses of the space benefited/arose from various land use patterns such as shopping, public agency, and residents; the various purposes encourages the diversity in a space to gather for various activities. Street Furniture that provided fundamental delineation of use such as parking line for motorcycle \& car, tree bed, and signage can create a space with high accessibility which is convenient for access and easy to navigate.

Negative aspects: With a high level of walkable \& accessible areas people tend to arbitrarily cross the road. This behavior can affect transportation movements and become unsafe. Multifunction space: various activities and much access cause the congestion on the sidewalk. Street furniture such as parking line on pavement and roadside aggravates problems of congestion (pedestrian \& transportation) as well as the resulting street parking obscures the urban vision.

(2) In Type B, where most human behaviors and activities are discouraged (Figures 11 and 13), the findings are as follows.

Positive aspects: The low level of walkable \& accessible areas arose from a high volume of transportation and both disconnected sides of street, for example the tunnel here was separately set in both sides might mitigate pedestrian impacting vehicle use. A low level of multifunctional space, due to poor land use patterns, such as mainly public agency and vacancies, can provide unobstructed vision and appearance of neat organization. Street Furniture provided very fundamental settings such as parking line for motorcycle \& car, tree bed, and sign can create a space with high accessibility, which is convenient for access and easy to navigate.

Negative aspects: Low levels of walkable \& accessible areas mean that people tend to abandon or isolate these spaces from each other. This can have negative effects on social interaction. A low level of multifunctional space is the main reason discouraging human activities. Street furniture such as parking lines on the pavement and roadside is set up in some segments. However, those areas without such furniture still have the problems of congestion (pedestrian \& transportation) or obscure urban vision, as there is no parking line in some cases, which means people can park anywhere.

(3) In Type C, which had neither frequent nor infrequent behaviors (Figure 13), the findings are as follows.

Positive aspects: Medium level of walkable \& accessible areas that arose from a high volume of low speed transportation and narrow pavement can create a walkable space with various activities and enhance social interaction. The high level of multifunctional space, due to various land use patterns and various kinds of shop houses, can attract various activities, promoting social interaction in cluster. Street furniture, which provided very fundamental settings such as parking lines for motorcycles \& cars, a tree bed, and signs, can create a space with free access, which is convenient for access and easy to navigate.

Negative aspects: With a medium level of walkable \& accessible areas, due to narrow pavement and free access, people tend to do their activities everywhere as pavement or roadway. This causes congestion and accidents. A high level of multifunction space, especially trading activities encroached pedestrian paths and roadways. Street furniture such as parking lines and tree strips on pavement and the roadside was set up to aggravate the problems of congestion (pedestrian \& transportation) as well as obscure the urban vision. Moreover, the lack of mini-trash bins is a reason for uncleanness.

In summary, the positives and negatives of the three street typologies are illustrated and clarified in Figure 14, which can be used as an input to improved designs for future streetscape proposals. 


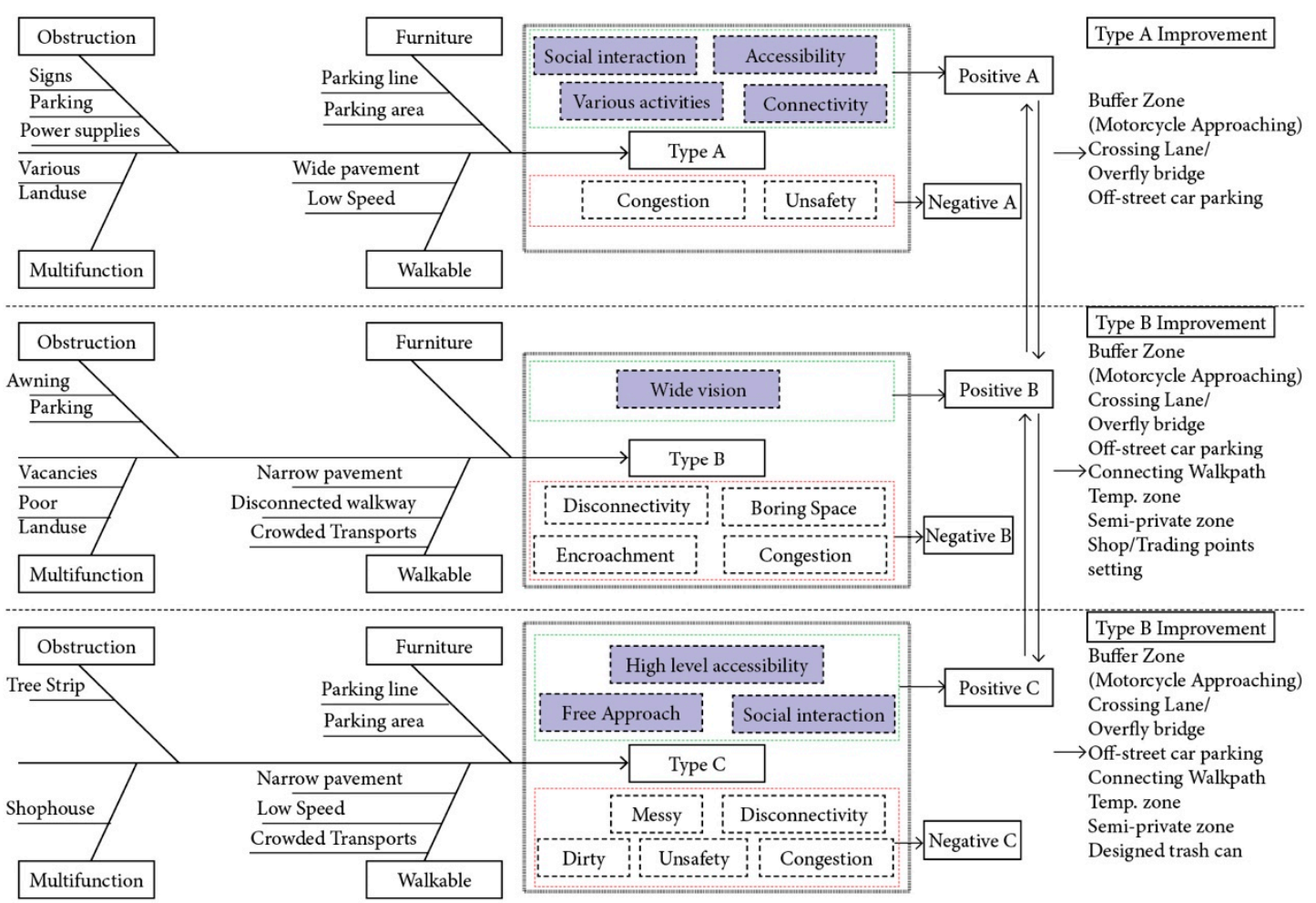

Figure 14. Cause and effect diagram analysis between three typologies of street space and implications.

\subsection{The Implication of Street Improvement}

Type A: To make streets accessible for people, improvements should be aiming to correct the problems in negative sides and remain the positive features (Figures 14 and 15). Firstly, providing proper buffer zones for motorcycle located between pavement and roadway for motorcycle and building the parking lots for car as well. Secondly, providing the suitable zebra crossing for pedestrians to connect both sides of street and create safer environment for users.

Type B: To make streets accessible for people, the improvements above should be aimed to correct the problems identified in the negative \& positive side discussion (Figures 14 and 15). Firstly, reducing the speed and volume of transportation. Widening the pavement for human activities. Secondly, considering the provision of the safe connection line between both sides and blocks with high density of users' activities along the street. Thirdly, considering the provision of some specific "functions" such as setting up a space for relaxation or parking purposes on pavement along segments occupied for public land use and vacancies. Fourthly, providing the buffer zones for motorized transportation.

Type C: To make streets accessible for people, the improvements should be aimed to (Figures 14 and 15). Firstly, widening the pavement for human activities. Secondly, applying the concept of sharing streets into permanent zone, pedestrian zone, public use zone, access zone and transportation zone. Thirdly, considering the provision of the safe connection line between both sides and blocks with high density of user's activities along the street. Fourthly, providing street furniture such as bench and trash bin to serve the basic needs. 


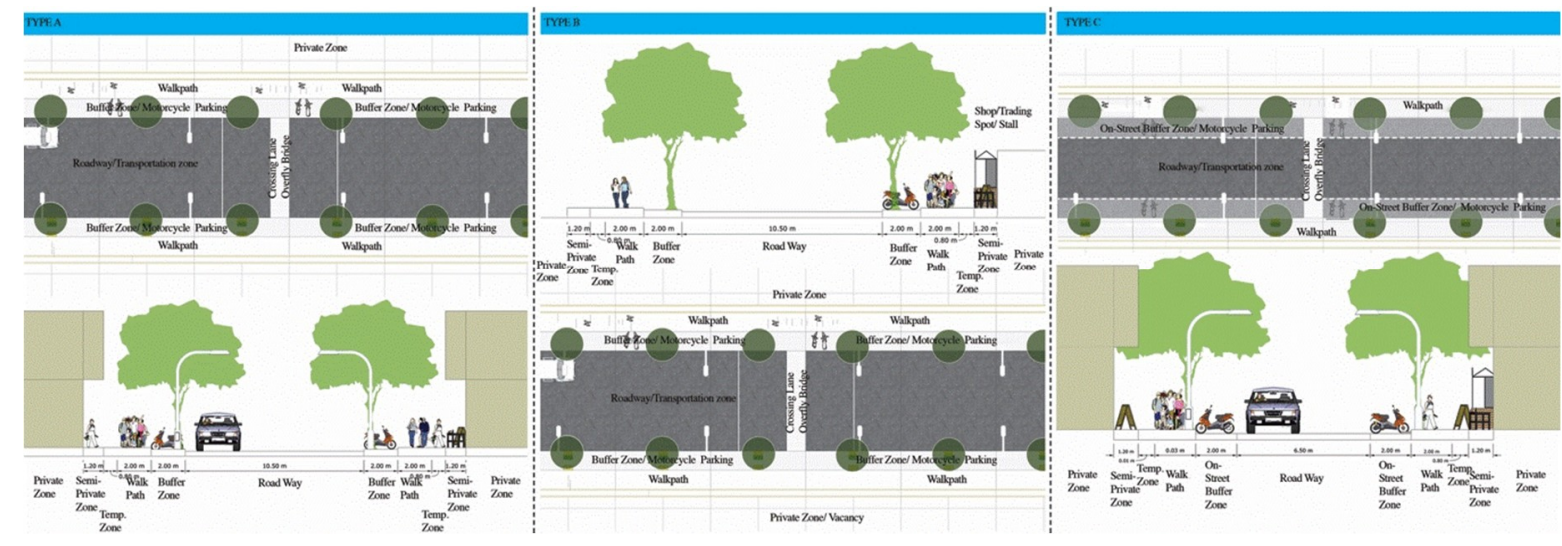

Figure 15. Visualizing one of the street improvement approaches for three types based on the findings.

\subsection{Managing Street Use}

In this research, the meaning of maintaining activities can be seen in behavior settings of old streets which can bring a positive impact on daily life of human beings. Unimproved streets have low-quality environment conditions and narrow pavements with the lack of physical settings like street furniture, visual objects, benches, greenery strips, and so on, compared with other improved streets. However, it is necessary to consider how to improve, manage and reasonably reorganize physical settings on the street during the process of street improvement. This study discovers that pavements are used for different purposes of residents, and also a medium space for human beings accessing their houses from roadsides and vice versa. Therefore, human activities in this space are often overlapped, especially some as leaving/coming with motorcycles, leaving/coming without motorcycles and walking to a particular destination. Nevertheless, it is necessary to consider the establishment of suitable space for motorbikes to avoid influencing activities on pavements. The current use of old streets also matches the research of Drummond (2000) on using the street space of the Vietnamese as a public space for their leisure and daily activities and where there is little distinction made between "public" and "private" [11].

The theory of street sharing is widely used because of its potential in helping human to share street and pavement space with others. It is commonly understood that in the Vietnamese context this hypothesis is unlikely to be applicable, as landlords think that they are entitled to use part of the pavement in front of their properties and allow no other individual to use it for any purpose, except for temporary activities such as passing through their houses. The research findings however lead to a new hypothesis about the distribution of space and functions based on blocks in which function settings attract some certain activities. This helps the sharing of street space to become more effective, encourages movements along streets for people to enjoy and makes those travels become easily managed and oriented. Now in Vietnam, the first step of street distribution based on functions is also implemented by naming streets with the same functions, in which settings only attract some certain behaviors/activities, this helps to reduce pressure on street space that accommodate a variety of human activities. Also, the importance of the access to environmental behaviors that aim to research on streets can improve physical appearance and functions while human activities or cultures are still maintained, the society is strengthened and sustainably develops.

The findings that have contributed to this research still have possible limitations. Additional time allotted to the survey can determine if all street behaviors in different time frame and different patterns of behaviors can be identified; which can confirm if the previous sampling was sufficient. To enhance this factor, users' activities would be recorded by multiple video cameras at different areas for the whole day [34]. In addition, precisely using behavior mapping in street space and matching them with the map is time-intensive and requires skill to do well. The employment of GPS GIS will help to save time and improve the accuracy of this process $[35,36]$. Human activities on streets can be affected 
by some factors such as weather, season, gender, and social conditions; the future research needs to classify their different behaviors in details, and discover roles of those elements.

Upcoming studies can include a deeper analysis of human behaviors in street space that support the appearance of different behaviors and their interaction with motorized transportation movements. On the other hand, the expansion of research scope on human behaviors in some space that only supports certain behaviors and their connection with other forms of space with different functions in the same road is needed.

\section{Conclusions}

This research aims to understand user's behaviors and their relationships with physical environment along unimproved streets in Da Nang city, Vietnam. The following conclusions are drawn:

(1) Six macro classifications of behaviors with 26 specific behaviors that form users' behaviors on Vietnamese street space were collected and analyzed. This helps to reveal how Vietnamese people use the street on a daily basis differently from citizens in other countries.

(2) The dominant behavior type along the street space is "Accessibility". Specifically, the subdivision of "leaving/coming with motorcycle" was the most frequent specific behavior. This proves the very high demand of travelling from/to roadways to/from pavements; also, owing to the widespread use of motorbikes in Vietnam, more attention needs to be paid to providing appropriate space for the access of motorbike drivers from roadways to pavements and vice versa. The second most frequent behavior along the street is "walking for destination". In old street space, the demand of walking in a short distance is huge, so it is advisable to consider safe sidewalks for users.

(3) On basis of PCA and CA, street space was categorized into 12 types of space that were illustrated by four common macro characteristics. These four factors may explain physical environment characteristics of street spaces as Multifunctional usage and Vision, Walking and Navigation, Recreation facility, and The Obstruction. These four factors should be seriously taken into consideration when designing/enhancing or managing street space matched with users' behavior or activities.

(4) Distribution of users' behaviors could be described by three street space types corresponding to usage patterns. Type A consists of group Gc2 that attracted most users' behaviors with high frequency. Type B consists of groups Ga3, Gb3, and Ga5 that were treated to discourage human activities in most behaviors. Type $\mathrm{C}$ contains $\mathrm{Ga} 2$ that was observed to contain neither frequent behaviors nor infrequent behaviors. The analysis of the relationship between behaviors and environment on street point out the key for contributing to the street improvement in the near future in Vietnam and maybe useful to other developing Asian countries with a similar cultural context.

(5) This research aims to discover different segments in the street where to form different patterns of use. This can lead to a hypothesis for urban planning and street environment based on functions to serve particular activities. This study also indicates the precise locations of street sections which attract many kinds of highly frequent activities, to support further research on the interaction of behaviors and the environment and suggest more specific solutions for street space design.

In this paper, the relationship between classified physical environment of street space and users' behaviors is systematically explained, providing a theoretical basis for and improving/developing processes to obtain proper street environment in the Vietnamese context. The goal of design and construction of effective street space should encourage activities in this space while minimizing conflicts with the operation of vehicles on roadways. This research discovers different segments in the street in which distinctive patterns of use are created. This can lead to a hypothesis for urban planning and street environment whose different areas are split based on functions for particular activities. In summary, users' behaviors and psychological needs should be taken into account in an objective, scientific and comprehensive way when urban environment planning and design are also examined. 
Author Contributions: Conceptualization, D.T.D.; Methodology, D.T.D., S.M., and R.N.; Software, D.T.D.; Validation, D.T.D., S.M., and R.N.; Formal Analysis, D.T.D.; Investigation, D.T.D.; Resources, D.T.D.; Data Curation, D.T.D.; Writing—Original Draft Preparation, D.T.D.; Writing—Review and Editing, D.T.D.; Visualization, D.T.D.; Supervision, S.M. and R.N; Project Administration, D.T.D.; Funding Acquisition, S.M.

Funding: This research received no external funding.

Acknowledgments: I would like to express my sincere gratitude to Japanese Government Scholarship (MEXT), for aiding my study in Japan and this research. Sincerest appreciation to the first author's supervisor, Prof. Suguru Mori for providing guidance and financial support. Finally, the first author extends his gratitude towards his brother-in-law, Jason Muirhead, for proofreading the paper.

Conflicts of Interest: The authors declare no conflict of interest.

\section{References}

1. Francis, M. Urban Open Space: Designing for User Needs; Island Press: Washington, DC, USA, 2003.

2. Park, S. A Preliminary Study on Connectivity and Perceived Values of Community Green Spaces. Sustainability 2017, 9, 692. [CrossRef]

3. Kim, S.; Kwon, H.-A. Urban Sustainability through Public Architecture. Sustainability 2018, 10, 1249. [CrossRef]

4. Lynch, K. The Image of the City; MIT Press: Cambridge, MA, USA, 1960; Volume 11.

5. Hassen, N.; Kaufman, P. Examining the role of urban street design in enhancing community engagement: A literature review. Health Place 2016, 41, 119-132. [CrossRef] [PubMed]

6. Gehl, J. Life Between Buildings: Using Public Space; Island Press: Washington, DC, USA, 2011.

7. Carmona, M.; Heath, T.; Oc, T.; Tiesdell, S. Public Places-Urban Spaces; Routledge: Abingdon-on-Thames, UK, 2012.

8. Mehta, V. Lively streets: Determining environmental characteristics to support social behavior. J. Plan. Educ. Res. 2007, 27, 165-187. [CrossRef]

9. Carmona, M. London's local high streets: The problems, potential and complexities of mixed street corridors. Prog. Plan. 2015, 100, 1-84. [CrossRef]

10. Barton, H. Land use planning and health and well-being. Land Use Policy 2009, 26, S115-S123. [CrossRef]

11. Drummond, L.B. Street scenes: Practices of public and private space in urban Vietnam. Urban Stud. 2000, 37, 2377-2391. [CrossRef]

12. Giang, L.A. Kinh tế vỉa hè-Kinh tế đô thị (Pavement Economic-Urban Economic). Vietnam. Archit. J. 2016, 200, 23-26. Available online: http:/ / kientrucvietnam.org.vn/paper/tap-chi-ktvn-so-200-2016/ (accessed on 23 December 2018).

13. Jacobs, J. The Death and Life of American Cities; Random House: New York, NY, USA, 1961.

14. Appleyard, D. Livable streets: Protected neighborhoods? Ann. Am. Acad. Polit. Soc. Sci. 1980, 451, $106-117$. [CrossRef]

15. Mehta, V. Walkable streets: Pedestrian behavior, perceptions and attitudes. J. Urban. 2008, 1, $217-245$. [CrossRef]

16. Hoehner, C.M.; Ramirez, L.K.; Elliott, M.B.; Handy, S.L.; Brownson, R.C. Perceived and objective environmental measures and physical activity among urban adults. Am. J. Prev. Med. 2005, 28, 105-116. [CrossRef]

17. Mateo-Babiano, I.B.; Ieda, H. Street space sustainability in Asia: The role of the Asian pedestrian and street culture. In Proceedings of the 7th International Conference of Eastern Asia Society for Transportation Studies, Dailian, China, 24-27 September 2007.

18. Espina, J.; Mori, S.; Nomura, R. An analysis of environment behavior relationships towards the design of a local mixed-used street: based on behavior settings of Belgium street in Cebu city, Philippines. Sustainability 2018, 10, 3230. [CrossRef]

19. Kaplan, R. The analysis of perception via preference: A strategy for studying how the environment is experienced. Landsc. Plan. 1985, 12, 161-176. [CrossRef]

20. Nhi, L.T.H. vỉa hè, không gian của cộng đồng (Pavement-community space). Vietnam. Archit. J. 2017, 6, 58-61. Available online: https:/ / www.tapchikientruc.com.vn/chuyen-muc/via-khong-gian-cua-cong-dong.html (accessed on 23 December 2018). 
21. Do, T.D.; Mori, S.; Nomura, R. Passenger's Attention Behaviors along Street Space: A Case Study of Da Nang City. J. Civ. Eng. Archit. 2018, 12, 245-261.

22. Jacobs, A.B. Great streets. ACCESS Mag. 1993, 1, 23-27.

23. Foresta, R.A. Comment: Elite values, popular values, and open space policy. J. Am. Plan. Assoc. 1980, 46, 449-456. [CrossRef]

24. Jacobs, J. The uses of sidewalks: Assimilating children. In The Death and Life of Great American Cities; Random House: New York, NY, USA, 1961.

25. Liebmann, G. Three good community-building ideas from abroad. Am. Enterp. 1996, 7, 72-74.

26. Biddulph, M. Street design and street use: Comparing traffic calmed and home zone streets. J. Urban Des. 2012, 17, 213-232. [CrossRef]

27. Coalition, N.C.S. National Complete Streets Coalition. 2011. Available online: http:/ / completestreets.org/ (accessed on 20 December 2018).

28. Klein, C.; Kuhnen, A.; Felippe, M.L.; Silveira, B.B. Place-centered or person-centered? Considerations about the behavioral mapping approach. Trends Psychol. 2018, 26, 593-616. [CrossRef]

29. Campbell, H.W.; Christman, S.P. Field techniques for herpetofaunal community analysis. Herpetol. Commun. 1982, 13, 193-200.

30. Heft, H. Ecological Psychology in Context: James Gibson, Roger Barker, and the Legacy of William James's Radical Empiricism; Psychology Press: Hove, UK, 2001.

31. Barker, R.G. Ecological Psychology: Concepts and Methods for Studying the Environment of Human Behavior; Stanford University Press: Redwood City, CA, USA, 1968.

32. Schoggen, P. Behavior Settings: A Revision and Extension of Roger G. Barker's Ecological Psychology; Stanford University Press: Redwood City, CA, USA, 1989.

33. Hall, E.T. "Proxemics: The Study of Man's Spatial Relations "In: I. Gladstone, ed. Man's Image in Medicine and Anthropology; International Universities Press: New York, NY, USA, 1963.

34. Li, Z.; Munemoto, J.; Yoshida, T. Analysis of Behaviors along the Waterside in a Chinese Residential Quarter. J. Asian Arch. Build. Eng. 2011, 10, 85-92. [CrossRef]

35. Pánek, J.; Benediktsson, K. Emotional mapping and its participatory potential: Opinions about cycling conditions in Reykjavík, Iceland. Cities 2017, 61, 65-73. [CrossRef]

36. Brown, G.; Rhodes, J.; Dade, M. An evaluation of participatory mapping methods to assess urban park benefits. Landsc. Urban Plan. 2018, 178, 18-31. [CrossRef] 